Objectives: To characterize the level of heterogeneity of RA patients in remission by identifying clusters based on the DAS28 components; and to describe inter and intra-class cluster demographic and clinical characteristics

Methods: Patients from Hospital Clínico San Carlos cohort, stored in a departmental electronic health record from January $1^{\text {st }}, 2000$ to December $30^{\text {th }}$, 2018, diagnose with RA according ACR 1986/ 2010 criteria were eligible for this study. Only observations with a DAS28 Erythrocyte Sedimentation Rate (ESR) value < 2.6 value were considered. ESR, patient's Global Health $(\mathrm{GH})$, and tender and swollen joints were used for calculating the clusters. Different aggregation levels for joints were studied as well as the input variable types. Isolated joints, joints grouped by the type of affectation (swollen or tender) or anatomic location or laterality aggregation levels were considered. Variables expressed as present or absent (i.e. dichotomous), continuous (count of joins) and categorical (type of joints) were also studied. Gower's distance, used for dealing with variables of different type, was employed to calculate the distance matrix. The number of suitable clusters was chosen from two to seven clusters based on the width value of a Silhouette analyses. Finally, Partitioning Around Medoids (PAM) was used as the clustering algorithm. Differences among clusters regarding demographic and clinical characteristics were analyzed using t-student chi2 test.

Results: 812 patients with 1,431 observations were analyzed in this study. The joint aggregation level which showed a highest Silhouette width value (0.708) was the anatomic one. In this aggregation level, five dichotomous variables (presence of tenderness and/or swelling in right and/or left shoulder, elbow, wrist, knee and hand (including both metacarpophalangeal and proximal interphalangeal joints) and two continuous variables (ESR and $\mathrm{GH}$ ) were used. Two clusters were found: the cluster A) with 1,305 observations and 742 patients and the B) with 126 observations and 115 patients. Cluster b) had a statistically significant higher DAS28-ESR value (higher number of tender and swollen joints, and higher $\mathrm{GH}$, but lower ESR), longer follow-up time (6.5 vs. 4.7 years), higher VAS-pain score (10 vs. 2 ), and higher HAQ score ( 0.25 vs. 0.12$)$. In addition, the proportion of patients treated with oral corticosteroids (63\% s. $50 \%)$ and biological therapy $(29 \%$ vs. $12 \%$ ) was higher.

Conclusion: We have identified two clinically distinct populations of RA patients in remission according to DAS28-ESR $<2.6$. Each subgroup could be associated with different outcomes during follow-up, such as radiographic progression or risk of relapse.

Disclosure of Interests: Alfredo Madrid García: None declared, Dalifer Freites Nuñez: None declared, Judit Font: None declared, Isabel Hernandez: None declared, Leticia León: None declared, Jose Ignacio Colomer: None declared, Isidoro González-Álvaro Grant/research support from: Roche Laboratories, Consultant of: Lilly, Sanofi, Paid instructor for: Lilly, Speakers bureau: Abbvie, MSD, Roche, Lilly, Benjamin Fernandez: None declared, J Angel Jover: None declared, Lydia Abasolo: None declared, Luis Rodriguez Rodriguez: None declared

DOI: 10.1136/annrheumdis-2020-eular.5750

\section{SAT0052 THERAPEUTIC STRATEGIES IN DIFFICULT-TO- TREAT RHEUMATOID ARTHRITIS: PRELIMINARY RESULTS OF A SYSTEMATIC LITERATURE REVIEW INFORMING THE 2020 EULAR RECOMMENDATIONS FOR THE MANAGEMENT OF DIFFICULT-TO-TREAT RHEUMATOID ARTHRITIS}

N. M. T. Roodenrijs ${ }^{1}$, A. Hamar ${ }^{2}$, M. Kedves ${ }^{3}$, G. Nagy ${ }^{4}$, J. M. Van Laar ${ }^{1}$, D. Van der Heijde ${ }^{5}$, P. Welsing ${ }^{1}{ }^{1}$ University Medical Center Utrecht, Department of Rheumatology \& Clinical Immunology, Utrecht, Netherlands; ${ }^{2}$ University of Debrecen, Department of Rheumatology, Debrecen, Hungary; ${ }^{3}$ BácsKiskun County Hospital, Department of Rheumatology, Kecskemét, Hungary; ${ }^{4}$ Semmelweis University, Department of Genetics, Cell- and Immunobiology \& Department of Rheumatology, 3rd Department of Internal Medicine, Budapest, Hungary; ${ }^{5}$ Leiden University Medical Center, Department of Rheumatology, Leiden, Netherlands

Background: Rheumatoid arthritis (RA) patients treated according to European League Against Rheumatism (EULAR) recommendations failing $\geq 2$ biological or targeted synthetic disease-modifying antirheumatic drugs (b/tsDMARDs) with a different mode of action who still have complaints which may be suggestive of active disease may be defined as suffering from 'difficult-to-treat RA' Management recommendations for RA focus predominantly on the earlier phases of the disease and specific recommendations for difficult-to-treat RA patients are currently lacking. ${ }^{1}$

Objectives: To systematically summarise evidence in the literature on pharmacological and non-pharmacological therapeutic strategies for difficult-to-treat RA patients, informing the 2020 EULAR recommendations for the management of difficult-to-treat RA.

Methods: A systematic literature review (SLR) was performed: PubMed, Embase and Cochrane databases were searched up to December 2019. Relevant papers were selected and appraised.

Results: Thirty articles were selected for therapeutic strategies in patients with limited DMARD options due to contraindications, 73 for patients in whom previous b/tsDMARDs were not effective ('true refractory RA'), and 51 for patients with predominantly non-inflammatory complaints. For patients with limited DMARD options, limited evidence was found on effective DMARD options for patients with concomitant obesity, and on safe DMARD options for patients with concomitant hepatitis B and C. In patients who failed $\geq 2$ bDMARDs, tocilizumab, tofacitinib, baricitinib, upadacitinib and filgotinib were found to be more effective than placebo, but evidence was insufficient to prioritise. In patients who failed $\geq 1$ bDMARD, there was a tendency of non-tumour necrosis factor inhibitor (TNFi) bDMARDs to be more effective than TNFi (Figure 1). Generally, b/tsDMARDs become less effective when patients failed more bDMARDs, this tendency was not clear for upadacitinib and filgotinib (Figure 2). In patients with predominantly non-inflammatory complaints (mainly function, pain and fatigue), exercise, education, psychological and self-management interventions were found to be of additional benefit.

Conclusion: This SLR underscores the scarcity of evidence on the optimal treatment of difficult-to-treat RA patients. As difficult-to-treat RA is a newly defined disease state, all evidence is to an extent indirect. Several b/tsDMARDs were found to be effective in patients who failed $\geq 2$ bDMARDs and generally effectiveness decreased with a higher number of failed bDMARDs. Additionally, a beneficial effect of non-pharmacological interventions was found on non-inflammatory complaints.
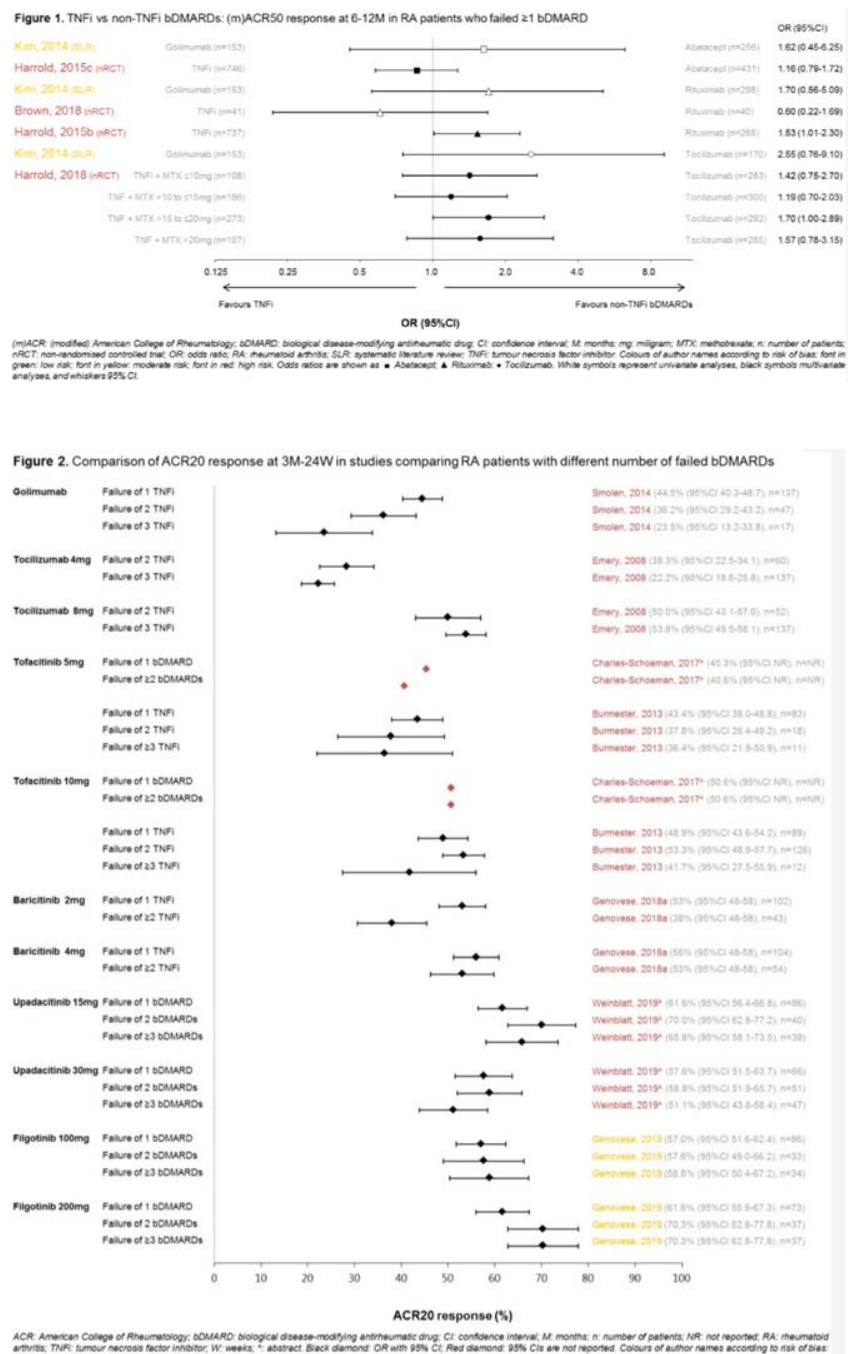


\section{References:}

[1] Smolen JS et al. Ann Rheum Dis 2020. Epub ahead of print. Disclosure of Interests: Nadia M. T. Roodenrijs: None declared, Attila Hamar: None declared, Melinda Kedves: None declared, György Nagy: None declared, Jacob M. van Laar Grant/research support from: MSD, Genentech, Consultant of: MSD, Roche, Pfizer, Eli Lilly, BMS, Désirée van der Heijde Consultant of: AbbVie, Amgen, Astellas, AstraZeneca, BMS, Boehringer Ingelheim, Celgene, Cyxone, Daiichi, Eisai, Eli-Lilly, Galapagos, Gilead Sciences, Inc., Glaxo-Smith-Kline, Janssen, Merck, Novartis, Pfizer, Regeneron, Roche, Sanofi, Takeda, UCB Pharma; Director of Imaging Rheumatology BV, Paco Welsing: None declared DOI: 10.1136/annrheumdis-2020-eular.4378

\section{SAT0053 ESTIMATING REAL-WORLD UNMET NEEDS FOR REACHING REMISSION IN THE FIRST YEAR FOLLOWING EARLY RA DIAGNOSIS: RESULTS FROM THE CANADIAN EARLY ARTHRITIS COHORT (CATCH)}

O. Schieir $^{1}$, S. J. Bartlett ${ }^{2,3}$, M. F. Valois4, L. Bessette ${ }^{5}$, G. Boire ${ }^{6}$, G. Hazlewood ${ }^{7}$, C. Hitchon ${ }^{8}$, E. Keystone ${ }^{9}$, J. Pope ${ }^{10}$, C. Thorne ${ }^{11}$, D. Tin ${ }^{11}$, V. Bykerk ${ }^{12}$ on behalf of Canadian Early Arthritis Cohort (CATCH) Investigators. ${ }^{1}$ Canadian Early Arthritis Cohort (CATCH), Montreal, Canada; ${ }^{2}$ Mc Gill University/MUHC, Montreal, Canada; ${ }^{3}$ Johns Hopkins Medicine, Baltimore, United States of America; ${ }^{2}$ Mc Gill University/MUHC, Montreal, Canada; ${ }^{5}$ Université de Laval, Quebec City, Canada; ${ }^{6}$ Université de Sherbrooke, Sherbrooke, Canada; ${ }^{7}$ University of Calgary, Calgary, Canada; ${ }^{8}$ University of Manitoba, Winnipeg, Canada; ${ }^{9}$ University of Toronto, Toronto, Canada; ${ }^{10}$ Western University, London, Canada; ${ }^{11}$ Southlake Regional Health Center, Newmarket, Canada; ${ }^{12}$ Hospital for Special Surgery, New York, United States of America

Background: Several composite RA disease activity indices are commonly used in clinical practice and research. Different disease activity indices however can be inconsistent in classifying remission (REM).

Objectives: 1) Compare remission prevalence across 4 common RA indices; 2) compare changes in remission across indices; and, 3) Identify predictors of persistent active disease across all indices, in real-world early RA patients over 1 year follow up.

Methods: Data were from patients with early RA (symptoms $<1$ year) enrolled in the Canadian Early Arthritis Cohort (CATCH) between 2007 and 2018. Participants had active disease at enrolment, were treated with csDMARDs and completed standardized clinical assessments every 3-months. Remission status was assessed using 4 indices: 1) DAS28<2.6 OR DAS28CRP $<2.5$, 2) CDAl $\leq 2.8$, 3) SDAI $\leq 3.3$, and 4) ACR/EULAR Boolean remission - SJC28, TJC28, CRP, PGA all $\leq 1$. T-tests/ chisquared tests were used to compare differences in remission prevalence by 1 year, and changes in remission before and after a QI program. Logistic regression was used to identify predictors of persistent active disease on all 4 indices.

Results: 1202 adults were eligible for this analysis. At enrolment, 877 (73\%) were women, mean (sd) age was 55 (14), average disease activity was high (DAS28 5.1 (1.4); CDAI 27 (14); SDAI 29 (15)). Prevalence of remission by 12-months follow up was $14-21 \%$ higher when estimated with the DAS28 compared with CDAI, SDAI and Boolean criteria, and $378(31 \%)$ did not achieve remission according to any of the 4 indices (Fig 1). Improvement in remission after a QI program however was similar across all 4 indices( +15-17\%). In adjusted logistic regression, Persistent active disease across all measures was most strongly associated with positive serostatus and smoking in men, and with obesity and more tender joints in women. Pain and lower education were predictors in BOTH men and women (Table 2)

\section{REM Prevalence Significantly Higher with DAS28}

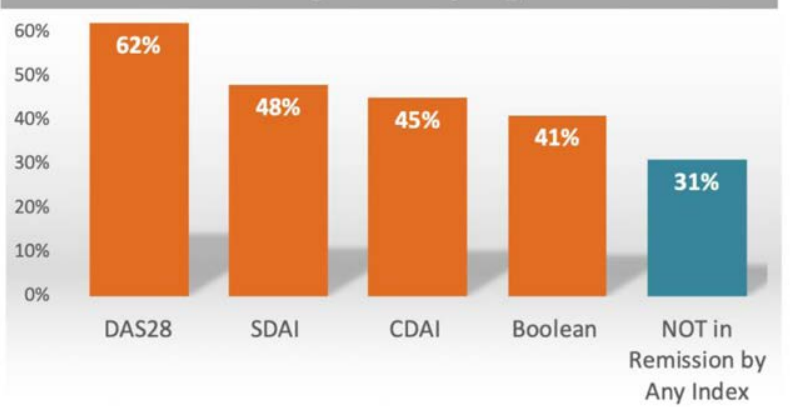

Figure 1. Prevalence of Remission by 12-Months across 4 Common RA Indices
Index DID NOT Impact Changes in REM

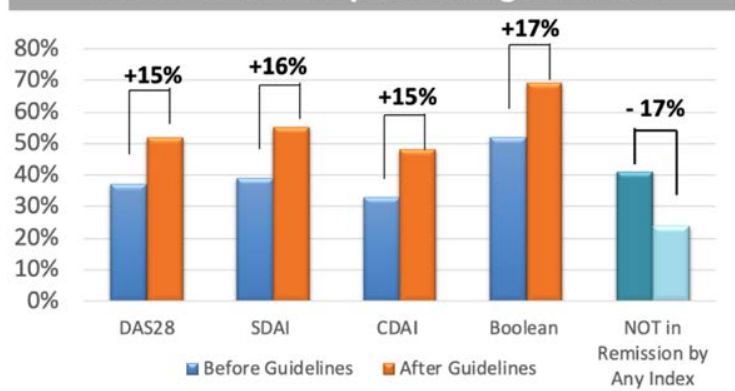

Figure 2. Change in Remission after Dissemination of Canadian RA Guidelines

Table 1. Multivariable Logistic Regression Predicting Persistent Active Disease by 12 -months across ALL RA indices

\begin{tabular}{lcc}
\hline & $\begin{array}{c}\text { Women } \\
\text { OR }(95 \% \mathrm{Cl})\end{array}$ & $\begin{array}{c}\text { Men } \\
\text { OR }(95 \% \mathrm{Cl})\end{array}$ \\
\hline Age & $1.01(1.00,1.02)$ & $1.03(1.00,1.05)$ \\
Female sex & NA & NA \\
Postsecondary education & $0.57(0.40,0.80)$ & $0.59(0.31,1.11)$ \\
Symptom duration, mos & $1.07(1.01,1.13)$ & $1.06(0.95,1.18)$ \\
RF+ or ACPA + & $1.15(0.75,1.77)$ & $2.32(1.02,5.29)$ \\
Current Smoking & $0.86(0.56,1.34)$ & $2.03(0.96,4.30)$ \\
Obese BMI > 30 & $2.19(1.43,3.34)$ & $0.95(0.43,2.10)$ \\
Comorbidity (RDCl 0-9) & $1.04(0.91,1.19)$ & $1.21(0.94,1.55)$ \\
TJC28 & $1.07(1.03,1.11)$ & $0.99(0.93,1.05)$ \\
SJC28 & $0.98(0.94,1.02)$ & $1.04(0.97,1.10)$ \\
Pain & $1.12(1.05,1.19)$ & $1.15(1.02,1.30)$ \\
\hline
\end{tabular}

Conclusion: In the absence of a single "best measure" that also takes in to account the patient's perspective, we estimate unmet needs for achieving remission in the first year of follow up in 1 in 3 ERA patients who did not achieve remission by ANY of the 4 indices.

References:

[1] Kuriya B, Sun Y, Boire G, Haraoui B, etal. Remission in Early Rheumatoid Arthritis - A Comparison of New ACR/EULAR Remission Criteria to Established Criteria. J Rheumatol 2012;39:1155-1158.

Disclosure of Interests: Orit Schieir: None declared, Susan J. Bartlett Consultant of: Pfizer, UCB, Lilly, Novartis, Merck, Janssen, Abbvie, Speakers bureau: Pfizer, UCB, Lilly, Novartis, Merck, Janssen, Abbvie, Marie-France Valois: None declared, Louis Bessette Grant/research support from: AbbVie, Amgen, Bristol-Myers Squibb, Celgene, Eli Lilly, Janssen, Merck, Novartis, Pfizer, Roche, Sanofi, UCB Pharma, Consultant of: AbbVie, Amgen, BristolMyers Squibb, Celgene, Eli Lilly, Janssen, Merck, Novartis, Pfizer, Roche, Sanofi, UCB Pharma, Speakers bureau: AbbVie, Amgen, Bristol-Myers Squibb, Celgene, Eli Lilly, Janssen, Merck, Novartis, Pfizer, Sanofi, Gilles Boire Grant/ research support from: Merck Canada (Registry of biologices, Improvement of comorbidity surveillance)

Amgen Canada (CATCH, clinical nurse)

Abbvie (CATCH, clinical nurse)

Pfizer (CATCH, Registry of biologics, Clinical nurse)

Hoffman-LaRoche (CATCH)

UCB Canada (CATCH, Clinical nurse)

BMS (CATCH, Clinical nurse, Observational Study Protocol IM101664. SEROPOSITIVITY IN A LARGE CANADIAN OBSERVATIONAL COHORT) Janssen (CATCH)

Celgene (Clinical nurse)

Eli Lilly (Registry of biologics, Clinical nurse), Consultant of: Eli Lilly, Janssen, Novartis, Pfizer, Speakers bureau: Merck, BMS, Pfizer, Glen Hazlewood: None declared, Carol Hitchon Grant/research support from: UCB Canada; Pfizer Canada, Edward Keystone Grant/research support from: AbbVie, Amgen, Bris tol-Myers Squibb, F. Hoffmann-La Roche Inc, Gilead, Janssen Inc, Lilly Pharmaceuticals, Pfizer Pharmaceuticals, Sanofi-Aventis, Consultant of: AbbVie, Amgen, AstraZeneca Pharma, Biotest, Bristol-Myers Squibb Company, Celltrion, Crescendo Bioscience, F. Hoffmann-La Roche Inc, Genentech Inc, Gilead, Janssen Inc, Lilly

Pharmaceuticals, Merck, Pfizer Pharmaceuticals, Sandoz, UCB., Speakers bureau: Amgen, AbbVie, Bristol-Myers Squibb Canada, F. Hoffmann-La Roche Inc., Janssen Inc., Merck, Pfizer Pharmaceuticals, Sanofi Genzyme, UCB Janet Pope Grant/research support from: AbbVie, Bristol-Myers Squibb, Eli 